\title{
A NEW COTTON SCALE FROM PANAMA
}

\author{
By T. D. A. Cockereli
}

A few weeks ago Mr. E. Bethel of Denver kindly forwarded to me some Coccidæ collected in the Panama Canal Zone by Mr. James Zetek. One of the species was seen at once to be a new Icerya; and as this genus is of more than ordinary interest, both from the economic and purely scientific points of view, the insect is described herewith.

\section{Icerya zeteki $\mathrm{n} . \mathrm{sp}$.}

On stems of an undetermined plant, having dark red color externally and much white pith within.

Female. Oval, about $4 \frac{1}{2} \mathrm{~mm}$. long, densely covered with white cottony tuftis' slightly stained with yellow; an elongated central mass of white wax is surrounded by a channel or depression, except anteriorly, and this is margined by a series of low quadrate tufts, about seven on each side, separated from each other only by slight depressions; outside of these, not separated by any interval, are low subquadrate tufts, about 10 on each side; in front is a suberect, horn-like but truncate, waxy projection, one $\mathrm{mm}$. or more long; while posteriorly a similar waxy projection, but much longer (up to $4 \mathrm{~mm}$.) projects over the ovisac, from which it is quite free. Ovisac $3-3 \frac{1}{2} \mathrm{~mm}$. long, very strongly fluted, white suffused with pink. No glassy filaments. Legs and antenna piceous. The mensurements of legs and antenna are in microns. Anterior legs: femur with trochanter, 640 ; tibia 512; tarsus with claw 272. Antenne 11-jointed, third joint longer than broad, fourth broader than long. Joints measuring (1.) 80 (2) 96, (3.) 104, (4.) 72, (5.) 64, (6 to 10) each 80, (11.) 160.

Larva light raspberry color; antennæ 6-jointed, the joints measuring ( 1 to 5 ) cach about 50, (6.) 160 ; last joint or club with no swelling at base; longest bristles on antenne about $830 \mu$; three pairs of long straight bristles on each side of caudal end, the longest $1360 \mu$ long (the body of the larva being only about 750); anterior to these are two very long curled bristles, then three shorter curled ones, then much shorter straight ones.

Closely allied to Icerya brasitiensis Hempel, but with the anterior and posterior waxy processes shorter, and wholly without the lateral posterior processes, on each side of the long one, which are so conspicuous in $I$. brasiliensis. In the larva of brasiliensis the posterior curled bristles of abdomen are not longer than the anterior ones. The ovisac of brasiliensis is creamy white, not pinkish.

\section{ACAROLETES PSEUDOCOCCI n. sp.}

By E. P. FEct, Albany, N. Y.

This interesting midge was reared in 1913 by Prof. H. J. Quayle from Pseudococcus citri Risso collected by him in Sicily. It is tentatively referred to the above named genus though it seems to have no very close affinities with $A$. tetranychi Kieff., the generic type. We are 